\title{
PENGARUH ABU TERBANG BATUBARA, KOMPOS TANDAN KOSONG KELAPA SAWIT, DAN MIKORIZA TERHADAP KETERSEDIAAN DAN SERAPAN FOSFOR, PERTUMBUHAN DAN PRODUKSI JAGUNG PADA ULTISOL
}

\section{The Effect of Coal Fly Ash, Oil Palm Empty Fruit Bunch Compost, and Mycorrhiza on the Availability and Uptake of Phosphorus, Growth and Yield of Maize on Ultisol}

\author{
Laili Fahimatul Mashfufah, Budi Prasetya* \\ Jurusan Tanah, Fakultas Pertanian, Universitas Brawijaya, Jl. Veteran no 1, Malang 65145 \\ *Penulis korespondensi: budiprasetya@ub.ac.id
}

\begin{abstract}
Ultisol has limitation to become agricultural land by low soil $\mathrm{pH}$, high saturation of $\mathrm{Al}$, poor macronutrients and low organic matter content. Maize production in Ultisol is faced with a lack of P. The purpose of this study was to determine the effect of coal fly ash (CFA), oil palm empty fruit bunch (OPEFB) and mycorrhiza to help increase the availability and uptake of phosphorus, growth and production of corn on Ultisol. The combination consisted of twelve treatments with 3 replications. The research was conducted in a glasshouse by planting corn on the planting media according to the treatment. Plant height and number of leaves were observed every week, at harvest (age 13 weeks) observed fresh weight and dry weight of shoot + root, fresh weight of cob with cornhusk, fresh weight of cob, weight of shelled seeds, production. P-total, P-available, P uptake, soil $\mathrm{pH}$, organic- $\mathrm{C}$, number of spores and percentage of root colonies were observed in the laboratory. The application of the combination of CFA and OPEFB and mycorrhiza did not have a significant effect on total-P, available- $\mathrm{P}$, soil $\mathrm{pH}$, organic-C, plant height, number of leaves, dry weight of shoot + root, fresh weight of cob with cornhusk and weight of shelled seeds. CFA, OPEFB and mycorrhiza influential in increasing P-uptake, dry weight of shoot + root, fresh weight of cob, production, number of spores and percentage of root colonies.
\end{abstract}

Keywords: coal fly ash, maize, mycorrbiza, oil palm empty fruit bunch, ultisol

\section{Pendahuluan}

Ultisol adalah salah satu jenis tanah yang tersebar luas mencapai 45.794 .000 ha atau sekitar $25 \%$ dari total luas daratan di Indonesia. Namun memiliki kendala umum berupa kemasaman tanah yang tinggi, $\mathrm{pH}$ rata-rata $<4,5$, kejenuhan $\mathrm{Al}$ tinggi, miskin hara makro terutama $\mathrm{P}, \mathrm{K}, \mathrm{Ca}$ dan $\mathrm{Mg}$, serta kandungan bahan organik yang rendah (Prasetyo dan Suriadikarta, 2006). Ultisol sering dikatakan sebagai tanah marginal karena kendala kesuburannya, oleh karena itu dilakukan pengelolaan untuk memperbaiki kualitas tanah pada Ultisol. Jagung merupakan komoditas yang cukup potensial untuk dibudidayakan karena selain dapat digunakan sebagai sumber karbohidrat dan protein juga sebagai bahan baku untuk ternak dan bahan baku industri. Sipayung et al. (2014) mengatakan bahwa pemberian pupuk padat di tanah Ultisol mampu menghasilkan produksi jagung berkisar 7-9 $\mathrm{t} \mathrm{ha}^{-1}$.

Untuk memproduksi komoditas jagung pada tanah Ultisol akan mengalami permasalahan terkait dengan unsur hara Fosfor $(\mathrm{P})$, jika tanaman jagung kekurangan unsur hara maka pertumbuhannya kurang 
maksimum atau dapat mengakibatkan tanaman jagung mati. Permasalahan pada tanah Ultisol dapat diperbaiki dengan penggunaan bahan organik, seperti pengaplikasian pupuk kompos. Salah satu bahan organik yang banyak tersedia di kawasan tanah Ultisol adalah tandan kosong kelapa sawit (TKKS). Haryawan et al. (2015) menyatakan bahwa kompos TKKS adalah kompos dari limbah organik hasil pabrik kelapa sawit yang masih dapat digunakan sebagai pupuk organik sehingga dapat dimanfaatkan untuk memenuhi ketersediaan unsur hara bagi tanah dan tanaman. Kompos TKKS juga mempunyai fungsi memperbaiki struktur tanah, sehingga dapat meningkatkan daya serap tanah terhadap air sehingga tanaman dapat tumbuh dan berproduksi dengan baik. Selain aplikasi pupuk kompos, pemilihan terhadap jenis bahan amelioran untuk memperbaiki kimia tanah sangat tergantung pada kemampuan, jumlah ketersediaan, dan kemudahannya memperoleh bahan amelioran tersebut. Salah satu amelioran yang mampu memperbaiki kimia tanah yang ketersediaannya cukup banyak adalah limbah dari penggunaan batubara sebagai energi yaitu abu terbang batubara. Abu terbang batubara (Fly ash) menurut Akbar et al. (2014) adalah material yang memiliki ukuran butiran yang halus berwarna keabu-abuan dan diperoleh dari hasil pembakaran batubara. Rini et al. (2009) mengemukakan bahwa abu terbang bersifat basa (mempunyai $\mathrm{pH}$ 10-13) dan mengandung kation-kation yang diperlukan tanaman seperti $\mathrm{Ca}, \mathrm{Mg}, \mathrm{Zn}, \mathrm{K}$, dan P serta tidak mengandung logam-logam berat yang berbahaya bagi tanah dan tanaman, sehingga dapat dijadikan amelioran untuk memperbaiki sifat kimia tanah.

Mengatasi permasalahan pada tanah Ultisol dapat dilakukan dengan mengaplikasikan Mikoriza Arbuskula (MA). Penggunaan mikoriza di tanah Ultisol diharapkan mampu membantu pertumbuhan tanaman yang terdapat di tanah Ultisol. Menurut Fahmissidqi (2016) berbagai macam mikoriza arbuskular pada tanaman memiliki manfaat besar bagi tanaman seperti, membantu meningkatkan penyerapan unsur-unsur hara dan nutrisi yang penting bagi tanaman. Hasil penelitian Simarmata dan Herdiani (2004) menunjukkan bahwa pada berbagai lahan marginal di Indonesia menunjukkan bahwa apliksi pupuk biologis seperti cendawan mikoriza arbuskula (Glomus sp. dan Gigaspora sp.) dapat meningkatkan produksi berbagai tanaman serta ketersediaan hara bagi tanaman antara $20-100 \%$. Berdasarkan uraian diatas maka digunakan kombinasi aplikasi abu terbang batubara, kompos tandan kosong kelapa sawit serta mikoriza untuk membantu meningkatkan ketersediaan dan serapan fosfor, serta pertumbuhan dan produksi jagung di tanah Ultisol.

\section{Bahan dan Metode}

\section{Tempat, waktu, dan bahan penelitian}

Penelitian dilakukan dalam pot di rumah kaca Universitas Tribhuwana Tunggadewi, Malang pada bulan Maret-Juni 2018. Analisa tanah dan tanaman dilakukan di Laboratorium Biologi dan Laboratorium Kimia Jurusan Ilmu Tanah, Fakultas Pertanian Universitas Brawijaya Malang. Alat yang digunakan yaitu cetok, pot, plastik, timbangan, ayakan bertingkat, cawan petri, sentrifuge, enlenmeyer, pipet, spektrofotometer, mikroskop. Bahan yang digunakan yaitu tanah Ultisol, pupuk pupuk dasar $100 \mathrm{~kg} \mathrm{~N}^{-1}$ dalam bentuk urea dan $50 \mathrm{~kg} \mathrm{~K}{ }_{2} \mathrm{O}$ ha $^{-1}$ dalam bentuk $\mathrm{KCl}$, kompos tandan kosong kelapa sawit (KTKKS), abu terbang batubara (ATB), mikoriza Glomus sp., benih jagung, gula dan aquades. Penelitian ini menggunakan Rancangan Acak Lengkap (RAL), yang terdiri dari 12 perlakuan dengan 3 kali ulangan.

Tanah Ultisol diperoleh dari Kabupaten Kutai Kartanegara, Kalimantan Timur. Kompos Tandan Kosong Kelapa Sawit (KTKKS) diambil dari lahan perkebunan kelapa sawit PT Surya Inti Sawit Kahuripan (Makin Group), Kecamatan Parenggean, Kabupaten Kotawaringin Timur, Kalimantan Tengah. Abu Terbang Batubara (ATB) diambil dari PLTU PT. Cahaya Fajar Kaltim di Desa Embalut, Kecamatan Tenggarong Seberang, Kabupaten Kutai Kartanegara.

\section{Pelaksanaan Penelitian}

Persiapan tanah

Tanah yang digunakan merupakan jenis tanah Ultisol yang didapatkan dari Kabupaten Kutai Kartanegara Kalimantan Timur. Tanah ini diletakkan dalam pot 
sebanyak $7 \mathrm{~kg}$ pot $^{-1}$ yang nantinya akan digunakan sebagai media tanam.

\section{Isolasi dan identifikasi mikoriza}

Isolasi dan identifikasi mikoriza menggunakan sampel tanah yang berasal dari sekitar daerah perakaran sehingga langsung dipengaruhi oleh akar tanaman. Metode yang digunakan dalam isolasi spora yaitu metode ayakan basah (wet sieving).

\section{Perlakuan dan penerapannya}

Setelah mempersiapkan tanah dalam pot, dilakukan aplikasi perlakuan sebanyak 12 perlakuan (Tabel 1). ATB dan KTKKS dicampurkan dengan tanah Ultisol yang sudah tersedia dalam pot kemudian diaduk agar merata. Mikoriza Glomus sp. yang sudah dikumpulkan dalam fial film akan diaplikasikan menggunakan contong tisu.

\section{Penanaman benih jagung}

Penanaman benih jagung dilakukan pada media pot plastik yang telah berisi tanah Ultisol $7 \mathrm{~kg}$ dengan 3 benih jagung dalam satu pot plastik. Selanjutnya pada 2 MST disisakan 1 tanaman yang terbaik, 2 tanaman lainnya dicabut.

\section{Pemberian pupuk dasar dan pemeliharaan tanaman}

Pupuk dasar yang diberikan adalah pupuk $\mathrm{N}$ dalam bentuk urea dengan dosis $100 \mathrm{~kg} \mathrm{~N} \mathrm{ha}^{-1}$ dan pupuk $\mathrm{K}$ dalam bentuk $\mathrm{KCl}$ dengan dosis $50 \mathrm{~kg}$ $\mathrm{K}_{2} \mathrm{O}$ ha $^{-1}$. Penyiraman dilakukan 2 kali sehari yaitu pagi dan sore untuk mempertahankan kelembaban dan mencukupi kebutuhan air tanaman jagung.
Penyulaman dilakukan apabila terdapat tanaman yang mati. Penyulaman yang dilakukan dengan menggunakan umur bibit tanaman yang sama agar pertumbuhannya sesuai dengan umur bibit tanaman yang tergantikan.

Penyiangan dilakukan setiap minggu dengan cara membersihkan gulma yang tumbuh di sekitar tanaman agar tidak mengganggu pertumbuhan tanaman jagung, penyiangan ini dilakukan secara mekanik yaitu dengan mencabut langsung gulma menggunakan tangan.

\section{Pengamatan dan pengumpulan data}

Jagung dipanen pada 90 HST. Pengamatan yang akan dilakukan meliputi P-total, Ptersedia, serapan $\mathrm{P}, \mathrm{pH}$ tanah, C-Organik, tinggi tanaman, jumlah daun, bobot segar dan bobot kering tajuk+akar, bobot segar tongkol berkelobot, bobot segar tongkol, bobot biji pipilan, produksi, jumlah spora dan persentase koloni akar.

\section{Analisis data}

Data hasil penelitian dianalisis dengan menggunakan analisis ragam (ANOVA). Apabila hasil ANOVA menunjukkan adanya pengaruh nyata pada setiap parameter yang diamati, maka akan dilakukan uji lanjut Duncan's Multiple Range Test (DMRT) pada taraf 5\% untuk mengetahui perbedaan setiap perlakuan.

Tabel 1. Perlakuan pada Penelitian

\begin{tabular}{|c|c|c|}
\hline No. & Kode & Deskripsi \\
\hline 1 & A0K0M0 & Kontrol = tanpa penambahan ATB, kompos atau mikoriza \\
\hline 2 & A0K0M1 & 0 t ATB ha-1 +0 t KTKKS ha-1+5 spora mikoriza kg-1 tanah \\
\hline 3 & A0K1M0 & 0 t ATB ha-1+ 10 t KTKKS ha-1+ 0 spora mikoriza $\mathrm{kg}^{-1}$ tanah \\
\hline 4 & A0K1M1 & 0 t ATB ha-1+ 10 t KTKKS ha-1+5 spora mikoriza $\mathrm{kg}^{-1}$ tanah \\
\hline 5 & A1K0M0 & 20 t ATB ha-1 +0 t KTKKS ha-1 +0 spora mikoriza kg-1 tanah \\
\hline 6 & A1K0M1 & 20 t ATB ha-1 +0 t KTKKS ha-1+ 5 spora mikoriza kg-1 tanah \\
\hline 7 & A1K1M0 & 20 t ATB ha-1 +10 t KTKKS ha-1 +0 spora mikoriza $\mathrm{kg}^{-1}$ tanah \\
\hline 8 & A1K1M1 & 20 t ATB ha-1+ 10 t KTKKS ha-1+ 5 spora mikoriza kg-1 tanah \\
\hline 9 & A2K0M0 & 40 t ATB ha-1+ 0 t KTKKS ha-1+ 0 spora mikoriza $\mathrm{kg}^{-1}$ tanah \\
\hline 10 & A2K0M1 & 40 t ATB ha-1+ 0 t KTKKS ha-1+ 5 spora mikoriza kg-1 tanah \\
\hline 11 & A2K1M0 & 40 t ATB ha-1+ 10 t KTKKS ha-1+ 0 spora mikoriza kg-1 tanah \\
\hline 12 & A2K1M1 & 40 t ATB ha-1+ 10 t KTKKS ha-1+ 5 spora mikoriza kg-1 tanah \\
\hline
\end{tabular}




\section{Hasil dan Pembahasan}

\section{P-total}

Hasil P-total tertinggi terdapat pada perlakuan A1K1M0 yaitu sebesar 67,73 ppm. Sedangkan Ptotal terendah terdapat pada kontrol yaitu sebesar 51,58 ppm (Gambar 1a). Pemberian ATB, KTKKS dan mikoriza tidak berpengaruh nyata terhadap P-total tanah. Hasil analisa akhir P-total jauh lebih rendah dibandingkan dengan analisa awal P-total, dimana nilai P-total awal sebesar 1452,78 ppm yang didapatkan dari penjumlahan Ptotal yang ada pada Ultisol, ATB dan KTKKS. Penurunan P-total ini dapat disebabkan karena kandungan $\mathrm{P}$ pada Ultisol dijerap oleh $\mathrm{Al}$ dan Fe. Syahputra et al. (2015) menyatakan bahwa kekurangan fosfat pada tanah Ultisol dapat disebabkan oleh kandungan fosfat dari bahan induk tanah yang pada umumnya sudah rendah. Rendahnya P total dapat juga disebabkan karena terfiksasi oleh mineral $\mathrm{Al}$ dan Fe.

Penguapan dan penyerapan dapat menyebabkan hilangnya kandungan hara $\mathrm{N}$ dan $\mathrm{K}$ rata-rata setengah dari jumlah semula, sedangkan $\mathrm{P}$ sekitar sepertiga dari jumlah semula. Kehilangan P dan $K$ dapat terjadi karena adanya pencucian senyawa nitrat oleh air hujan (Sinuraya et al., 2015).

\section{P-tersedia}

P-tersedia merupakan jumlah kandungan fosfat yang tersedia dalam tanah yang dapat diserap oleh tanaman. P-Tersedia tertinggi terdapat pada perlakuan A1K1M0 yaitu sebesar 5,19 ppm, sedangkan yang terendah terdapat pada perlakuan kontrol yaitu sebesar 3,2 ppm (Gambar 1b). Perlakuan tanpa mikoriza menunjukkan ketersediaan $\mathrm{P}$ yang lebih tinggi daripada perlakuan yang lain. Hal ini dapat disebabkan karena $\mathrm{P}$ yang terlarut dalam tanah yang diberi mikoriza langsung tersedia dan diserap oleh tanaman.

Pemberian ATB, KTKKS dan mikoriza tidak berpengaruh nyata terhadap P-tersedia. Tingginya P-tersedia pada perlakuan A1K0M0 dan A1K1M0 menunjukkan bahwa perlakuan tersebut tidak banyak menyerap $\mathrm{P}$, sehingga $\mathrm{P}$ yang tersedia dalam tanah masih cukup banyak. Nasution et al. (2014) menyatakan penurunan P-tersedia dapat terjadi karena $\mathrm{P}$ yang terikat dalam tanah dan terlarut akibat enzim fosfatase mikoriza tersebut langsung tersedia diserap oleh tanaman inang, sehingga pemberian mikoriza tidak berpengaruh nyata terhadap P-tersedia tanah, namun berpengaruh nyata terhadap serapan P tanaman inang. Menurut Prasetyo dan Suriadikarta (2006) kekurangan P pada tanah Ultisol dapat disebabkan oleh kandungan $\mathrm{P}$ dari bahan induk tanah yang memang rendah, atau kandungan $\mathrm{P}$ sebenarnya sudah tinggi, namun tidak tersedia untuk tanaman karena terjerap oleh unsur lain seperti $\mathrm{Al}$ dan Fe.

Penambahan K'TKKS mampu meningkatkan ketersediaan P karena adanya proses dekomposisi. Pemberian kompos dapat meningkatkan P-tersedia karena adanya proses dekomposisi dan mineralisasi dari kompos sehingga meningkatkan adsorpsi P. Pemberian abu terbang batubara dapat meningkatkan ketersediaan P karena silikat dapat menggantikan posisi $\mathrm{P}$ yang dijerap, sehingga anion $\mathrm{P}$ dikeluarkan ke dalam larutan tanah kemudian dijerap oleh silikat. Pemberian silikat dapat meningkatkan kadar $\mathrm{P}$ tanah menjadi bentuk yang lebih tersedia bagi tanaman.

\section{Serapan $P$}

Serapan P dapat diketahui dengan cara mengalikan konsentrasi $\mathrm{P}$ dengan produksi bobot kering per tanaman. Serapan P tertinggi terdapat pada perlakuan A2K1M1 yaitu sebesar 0,081 g tanaman-1, sedangkan serapan $\mathrm{P}$ terendah terdapat pada perlakuan kontrol yaitu sebesar 0.013 gtan aman-1 (Gambar 1c). Penambahan ATB, KTKKS dan mikoriza berpengaruh sangat nyata terhadap serapan P. Adanya pemberian mikoriza meningkatkan serapan $\mathrm{P}$ lebih tinggi dibandingkan dengan perlakuan tanpa mikoriza. Hifa dapat menyerap hara dalam tanah meskipun kondisi tanah tersebut ketersediaan haranya rendah, yang mana akar tidak mampu untuk menyerap, sehingga pengaruh CMA terhadap serapan hara tinggi. Hasanudin dan Bambang (2004) menjelaskan adanya peningkatan serapan $\mathrm{P}$ diduga karena mikoriza beserta hifanya mampu memperluas daerah serapan hara di sekitar perakaran dan mikoriza mempercepat gerakan fosfor kedalam akar tanaman. 
Peningkatan serapan P diduga karena ATB dan KTKKS memiliki kandungan $\mathrm{P}$ yang tinggi sebesar 1.378,56 ppm (ATB) dan 3.700 ppm (KTKKS) yang dilepaskan. Fahrunsyah et al. (2018) menjelaskan bahwa kandungan P tersedia kemungkinan meningkat karena $\mathrm{P}$ tersedia dan $\mathrm{P}$ organik dari KTKKS, kandungan $\mathrm{P}$ tersedia dalam campuran ATB dan KTKKS cenderung meningkat seiring meningkatnya proporsi K'TKKS dalam campuran menunjukkan bahwa sumber utama $\mathrm{P}$ dalam campuran berasal dari kompos tandan kosong kelapa sawit.
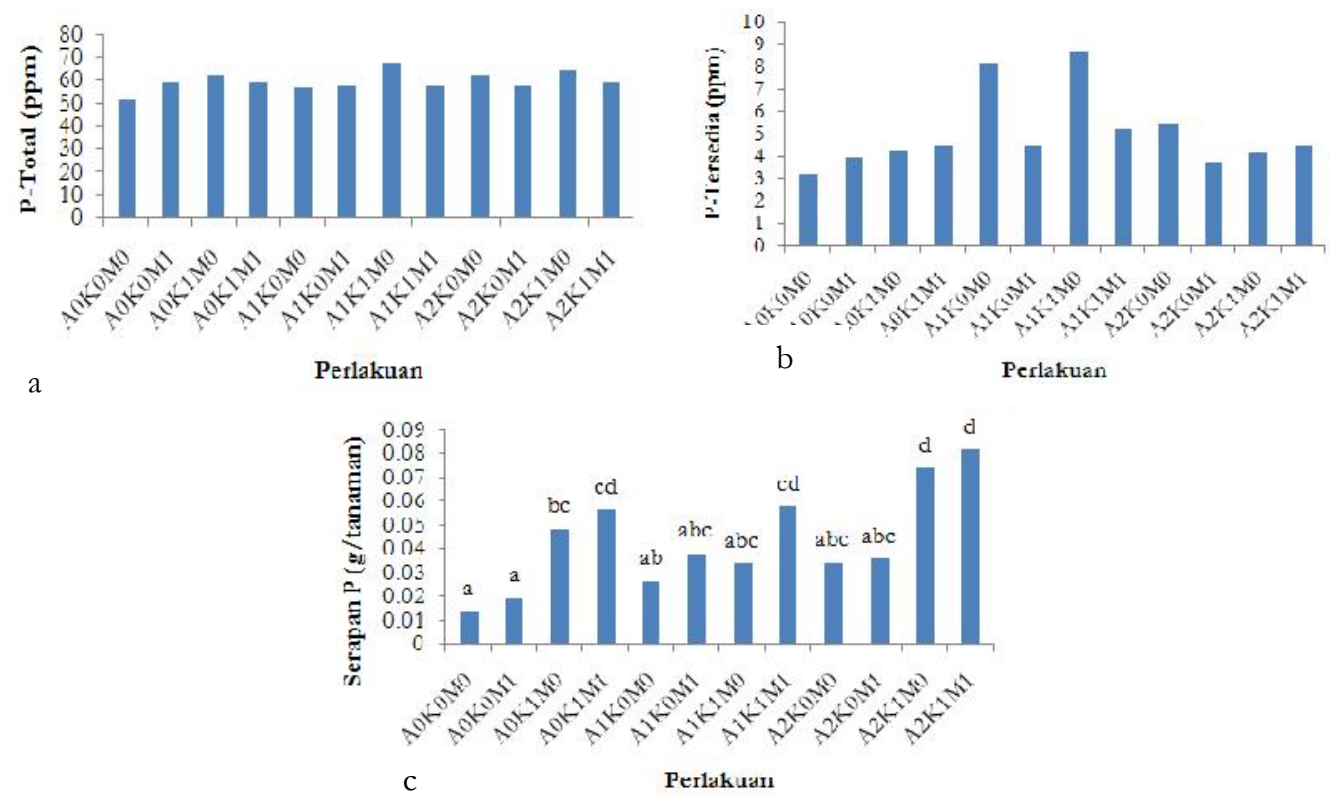

Gambar 1 (a). Hasil analisis P-total tanah pada 90 HST, (b). Kadar P-tersedia tanah pada 90 HST, (c). Hasil analisis serapan P.

Keterangan: Kode perlakuan tertera pada Tabel 1; huruf yang sama diatas batang menunjukkan perlakuan tidak berbeda nyata pada uji lanjut Duncan $5 \%$.

\section{pH tanah}

$\mathrm{pH}$ tertinggi terdapat pada perlakuan A0K1M0 yaitu sebesar 4,17, sedangkan $\mathrm{pH}$ terendah terdapat pada perlakuan kontrol yaitu sebesar 4,03 (Gambar 2a). Pemberian ATB, KTKKS dan mikoriza tidak berpengaruh nyata terhadap $\mathrm{pH}$. Penambahan ATB dan KTKKS yang seharusnya dapat meningkatkan $\mathrm{pH}$ pada Ultisol tidak nampak secara keseluruhan. Menurut Fahrunsyah et al. (2018) penambahan ATB, KTKKS dan campuran tanah Ultisol dapat meningkatkan $\mathrm{pH}$ tanah dan menurunkan jumlah $\mathrm{Al}$ dan $\mathrm{H}$ yang dapat ditukar, yang seiring dengan peningkatan dosis KTKKS.

Disisi lain penambahan mikoriza tidak selalu meningkatkan $\mathrm{pH}$ tanah, karena aktifitas mikoriza yang dapat menghasilkan asam organik. Menurut Musafa et al. (2015) menurunnya $\mathrm{pH}$ tanah dapat disebabkan oleh kemampuan mikoriza dalam menghasilkan asam organik dan mampu meningkatkan populasi mikroorganisme lain dalam tanah. Adanya mikroorganisme tersebut berperan dalam mendekomposisi bahan organik yang mana akan melepaskan senyawa karbon dioksida $\left(\mathrm{CO}_{2}\right)$, lalu akan membentuk asam karbonat dan melepaskan ion $\mathrm{H}^{+}$ke dalam larutan tanah sehingga menyebabkan $\mathrm{pH}$ tanah menurun.

\section{C-organik}

Nilai C-Organik tertinggi terdapat pada perlakuan A2K1M1 yaitu sebesar 1,37\%, sedangkan nilai terendah terdapat pada perlakuan kontrol yaitu sebesar 0,9\% (Gambar 2c). Kombinasi ATB, KTKKS dan mikoriza tidak memberikan pengaruh yang nyata terhadap C-organik. Pemberian mikoriza dapat meningkatkan kandungan C- 
organik dalam tanah, dimana karbon merupakan makanan mikroorganisme tanah sehingga dengan meningkatnya karbon menunjukkan adanya mikoriza dalam tanah. Karbon merupakan makanan bagi mikroorganisme yang berada di dalam tanah seperti mikoriza, sehingga keberadaan karbon dapat membantu meningkatkan sistem kerja mikoriza dalam mempercepat proses dekomposisi tanah. Mikoriza mampu menambahkan karbon organik dari tanaman inang dan memproduksi glomalin atau glicoprotein yang relatif tahan lama terhadap dekomposisi sehingga dapat berfungsi sebagai sumber karbon dan kemantapan agregat (Musafa et al., 2015). Meskipun kandungan C-organik dalam ATB hanya $0,82 \%$ dan pada Ultisol $1,23 \%$, namun pada KTKKS mengandung COrganik yang tinggi yaitu 17,3\%. Oleh sebab itu peningkatan C-organik diiringi dengan peningkatan dosis kompos yang diberikan. Semakin tinggi dosis kompos yang diaplikasikan maka peningkatan Corganik juga semakin tinggi, karena karbon merupakan penyusun utama kompos.
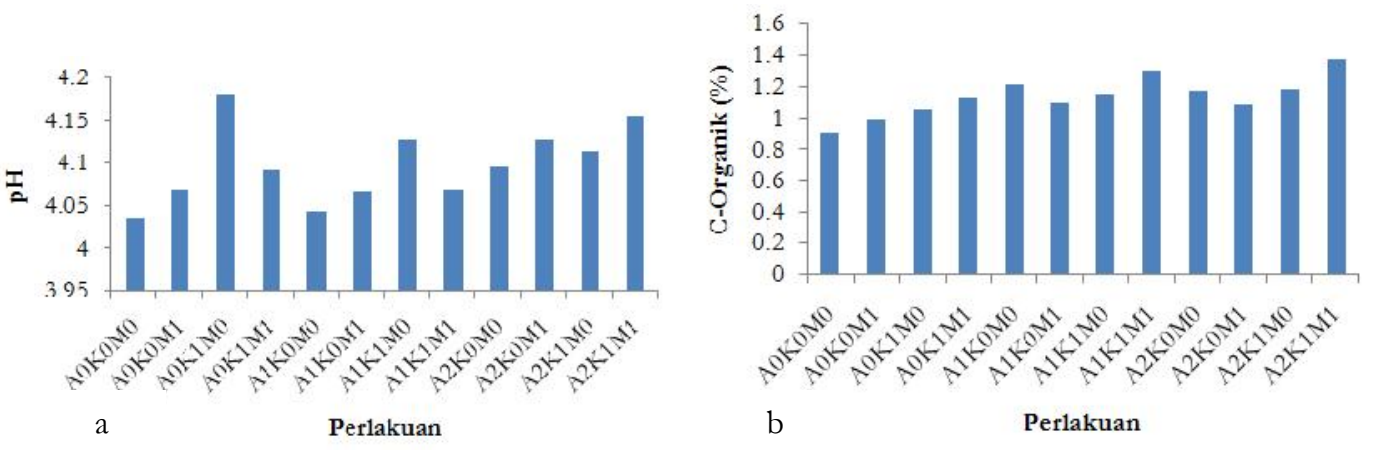

Gambar 2 (a). Hasil analisis pH pada 90 HST, (b). Kadar C-organik tanah pada 90 HST. Keterangan: Kode perlakuan tertera pada Tabel 1

\section{Tinggi tanaman}

Tinggi tanaman jagung terus meningkat sampai pada 8 MST, selanjutnya pada 9 MST sampai 13 MST mengalami pergerakan yang cenderung stabil (Gambar 3a). Tinggi tanaman tertinggi didapatkan pada perlakuan A1K1M1, sedangkan tinggi tanaman terendah terdapat pada kontrol. Kombinasi aplikasi abu terbang batubara, kompos tandan kosong kelapa sawit dan mikoriza tidak menunjukkan adanya pengaruh yang nyata pada semua perlakuan.

Aplikasi ATB tidak memiliki pengaruh yang signifikan pada pertumbuhan tanaman, meskipun kandungan $\mathrm{P}$ yang dimiliki tergolong tinggi namun pada fase vegetatif tanaman cenderung membutuhkan $\mathrm{N}$, sedangkan kandungan $\mathrm{N}$ dalam ATB hanya $0.5 \%$. Made (2010) menyatakan bahwa kecukupan unsur hara Nitrogen dalam tanah akan membantu tanaman dalam proses perkembangan fase vegetatif yang cepat, karena Nitrogen sangat dibutuhkan oleh jaringan meristem pada saat pembelahan sel, pembesaran sel dan perpanjangan sel untuk membentuk protoplasma dan dinding sel yang baru. Meskipun demikian KTKSS memiliki kandungan $\mathrm{N}$ sebesar 1,56\% sehingga perlakuan A1K1M1 menunjukkan tinggi tanaman terbaik dari perlakuan lainnya. Selain itu Glomus dapat memberikan pengaruh terhadap pertumbuhan tanaman meskipun tanah tersebut terkontaminasi logam berat yang terdapat pada abu terbang batubara, karena glomalin mampu mengikat logam berat dalam tanah dan menurunkan konsentrasi logam berat di sekitar miselium (Suharno dan Retno, 2013).

\section{Jumlah daun}

Jumlah daun terendah terdapat pada perlakuan kontrol, sedangkan jumlah daun tertinggi terdapat pada perlakuan A2K0M1. Jumlah daun yang dihitung merupakan jumlah daun yang masih hijau dan 
menempel pada batang. Jumlah daun terus meningkat sampai pada 8 MST, kemudian pada 9 MST konstan, namun pada 10 MST mengalami penurunan, setelah itu pada 11 MST jumlah daun meningkat tetapi pada 12 dan 13 MST jumlah daun menurun (Gambar 3b). Pemberian ATB, KTKKS dan mikoriza tidak berpengaruh nyata terhadap jumlah daun. Penurunan jumlah daun disebabkan oleh daun tanaman jagung yang rontok karena kondisi lingkungan yang kurang mendukung. Rendahnya kandungan $\mathrm{N}$ dalam tanah diduga menjadi salah satu penyebab menurunnya jumlah daun, karena pada masa vegetatif jagung membutuhkan $\mathrm{N}$ yang berperan dalam membantu pembentukan daun. Meskipun demikian unsur hara yang tersedia dalam tanah tetap dapat membantu proses pembentukan daun. Menurut Ekowati dan Nasir (2011) tingginya kadar unsur hara tersedia tersebut dapat memacu aktivitas hormonal dalam pembentukan daun.
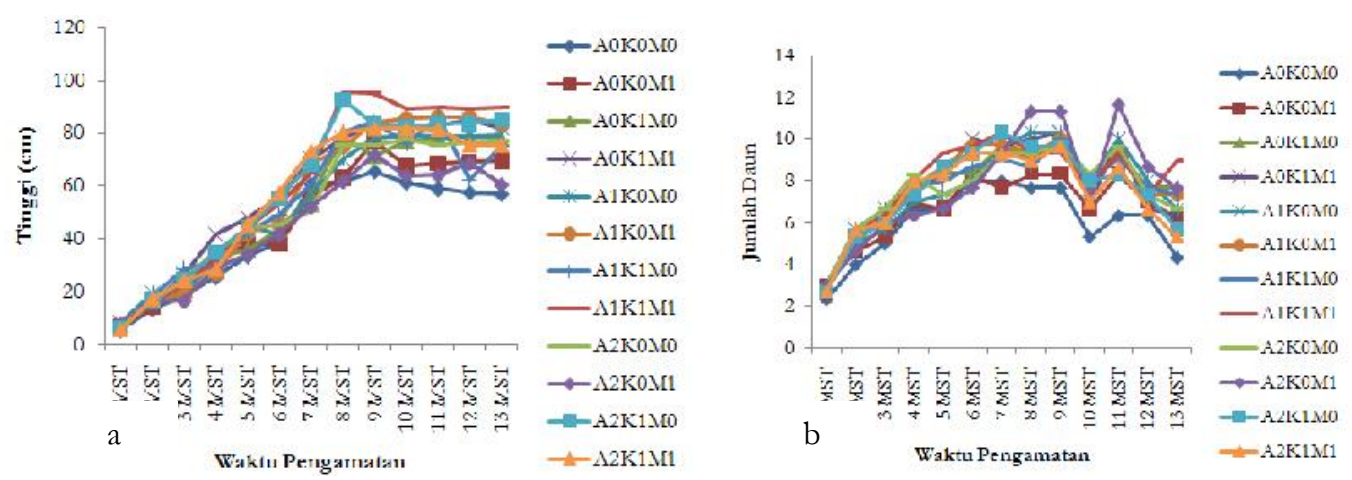

Gambar 3 (a). Tinggi tanaman 1 MST sampai 13 MST, (b). Jumlah daun 1 MST sampai 13 MST. Keterangan: Kode perlakuan tertera pada Tabel 1

\section{Bobot segar dan bobot kering tajuk+akar}

Bobot segar tajuk+akar tertinggi terdapat pada perlakuan A2K1M1, sedangkan bobot segar tajuk+akar terendah terdapat pada perlakuan kontrol. Selanjutnya bobot kering tajuk+akar tertinggi terdapat pada perlakuan A2K1M0, sedangkan bobot kering tajuk+akar terendah terdapat pada perlakuan kontrol (Gambar 4). Bobot segar tajuk+akar tidak menunjukkan pengaruh yang nyata, hal ini diduga pada saat tanaman masih dalam pot, kemampuan menyimpan air pada setiap perlakuan sama, oleh karena itu hanya bobot kering yang berpengaruh nyata. Saat fase vegetatif dan fase generatif jagung menyimpan banyak air, sehingga saat dimasukkan dalam oven jagung tersebut kehilangan air yang terkandung didalamnya. Air berperan dalam pelarutan unsur hara dalam tanah sehingga dapat diserap tanaman. Ekowati dan Nasir (2011) menyatakan bahwa tanaman membutuhkan unsur hara dalam bentuk ion, baik dalam bentuk anion maupun kation kecuali unsur $\mathrm{C}, \mathrm{H}$ dan $\mathrm{O}$. Sehingga diperlukan air untuk mengubah unsur hara menjadi larutan yang berisi ion agar dapat diserap tanaman.

Mikoriza mampu meningkatkan serapan $\mathrm{P}$, sehingga mampu meningkatkan bobot segar tanaman jagung. Perlakuan pemberian mikoriza menunjukkan nilai yang lebih tinggi dibandingkan dengan perlakuan tanpa mikoriza. Sesuai dengan pernyataan Same (2011) peran mikoriza arbuskula terhadap pertumbuhan tanaman disebabkan meningkatnya hara yang diserap, yang diiringi dengan luasnya permukaan serapan atau kemampun mikoriza dalam memobilisasi sumber hara yang sulit tersedia. Sehingga sangat penting terhadap pertumbuhan tanaman terutama dalam penyerapan P.

\section{Bobot segar tongkol berkelobot}

Bobot segar tongkol berkelobot pada tanaman yang tertinggi terdapat pada perlakuan A2K1M1 yaitu sebesar 134,67 g, sedangkan yang terendah terdapat pada perlakuan kontrol yaitu sebesar 57,33 g (Gambar 5a). Pemberian ATB, KTKKS 
dan mikoriza tidak berpengaruh nyata terhadap bobot segar tongkol berkelobot. Peranan P sangat penting dalam pembentukan tongkol jagung, namun $\mathrm{P}$ yang tersedia masih belum mencukupi dalam proses pembentukan tongkol. Subandi et al. (2017) menyatakan bahwa peranan unsur hara N dan $\mathrm{P}$ pada masa vegetatif seimbang tetapi ketika memasuki masa generatif maka peranan $\mathrm{P}$ lebih dominan karena $\mathrm{P}$ sangat diperlukan dalam proses pembentukan bunga, buah dan biji.

\section{Bobot segar tongkol}

Bobot segar tongkol yang tertinggi yaitu pada perlakuan A2K1M1 yaitu sebesar $71 \mathrm{~g}$, sedangkan yang terendah terdapat pada perlakuan kontrol yaitu sebesar 23 g (Gambar 5b). Pemberian ATB,
KTKKS dan mikoriza menunjukkan pengaruh yang nyata terhadap bobot segar tongkol. Kecukupan P dapat meningkatkan kualitas tongkol jagung, pada pembentukan tongkol dibutuhkan $\mathrm{N}$ dan $\mathrm{P}$ dalam proses fotosintesis dan metabolisme karbohidrat. Menurut Subandi et al. (2017) proses pembentukan tongkol terjadi melalui fotosintesis yang melibatkan $\mathrm{N}$ dan $\mathrm{P}$, dimana $\mathrm{N}$ merupakan komponen klorofil, dan $\mathrm{P}$ merupakan bagian esensial proses fotosintesis dan metabolisme karbohidrat sebagai fungsi regulator yang membagi hasil fotosintesis antara sumber dan organ reproduksi.

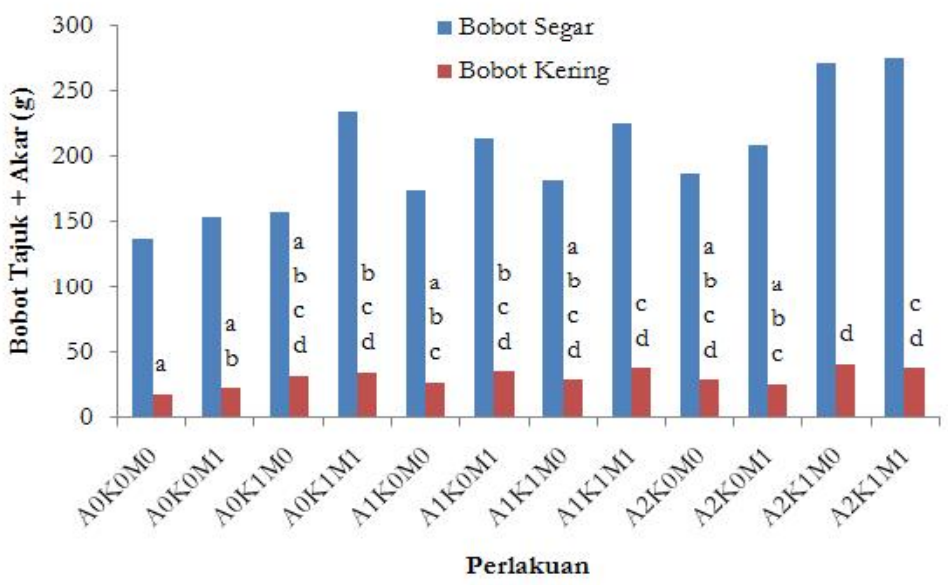

Gambar 4. Rerata bobot tajuk+akar.

Keterangan: huruf yang sama diatas batang menunjukkan perlakuan tidak berbeda nyata pada uji lanjut Duncan 5\%. Kode perlakuan tertera pada Tabel 1.

\section{Bobot biji pipilan}

Bobot segar biji kering pipilan yang tertinggi yaitu pada perlakuan A2K1M0 yaitu sebesar 13,4 g, sedangkan yang terendah terdapat pada perlakuan kontrol yaitu sebesar 0,14 g (Gambar 5c). Pemberian ATB, KTKKS dan mikoriza tidak berpengaruh nyata terhadap biji kering pipilan. $\mathrm{Hal}$ ini disebabkan karena kurangnya $\mathrm{P}$ dalam tanah, sehingga mengakibatkan tidak terbentuknya biji pada tongkol jagung. Meskipun telah dilakukan penambahan abu terbang batubara, kompos tandan kosong kelapa sawit dan mikoriza, namun masih kurang untuk produksi jagung. Hasanudin dan Bambang (2004) menjelaskan bahwa meningkatnya ketersediaan $\mathrm{P}$ dalam tanah dan serapan $\mathrm{P}$ oleh tanaman akan meningkatkan hasil pipilan jagung karena dalam pembentukan pipilan jagung unsur $\mathrm{P}$ sangat dibutuhkan. Herviyanti et al. (2012) juga menjelaskan bahwa peningkatan bobot biji dipengaruhi oleh $\mathrm{P}$, dimana pemberian pupuk $\mathrm{P}$ pada berbagai dosis mempunyai kualitas biji yang lebih bagung dibandingkan dengan tanpa pemberian pupuk $P$.

\section{Produksi}

Produksi jagung yang tertinggi pada perlakuan A2K1M1 yaitu sebesar 118,33 kg $\mathrm{ha}^{-1}$, sedangkan produksi terendah terdapat pada perlakuan kontrol yaitu sebesar 38,33 
$\mathrm{kg} \mathrm{ha}^{-1}$ (Gambar 6). Aplikasi ATB, KTKKS dan mikoriza memberikan pengaruh yang nyata terhadap produksi jagung, namun dapat mempengaruhi peningkatan produksi jagung, karena kandungan hara yang terdapat pada ATB dan KTKKS mampu mencukupi kebutuhan hara jagung, sedangkan mikoriza berperan dalam menyerap P yang dibutuhkan dalam pembentukan tongkol jagung. Sehingga peningkatan tongkol jagung diiringi dengan meningkatnya produksi jagung. Jika dibandingkan dengan produksi jagung nasional, hasil setiap perlakuan masih sangat rendah. Menurut Subandi et al. (2017) produksi jagung nasional pada tahun 2014 mencapai 4,9 tha1. Pemupukan dan pengelolaan tanah sering menjadi faktor utama yang mempengaruhi hasil jagung.
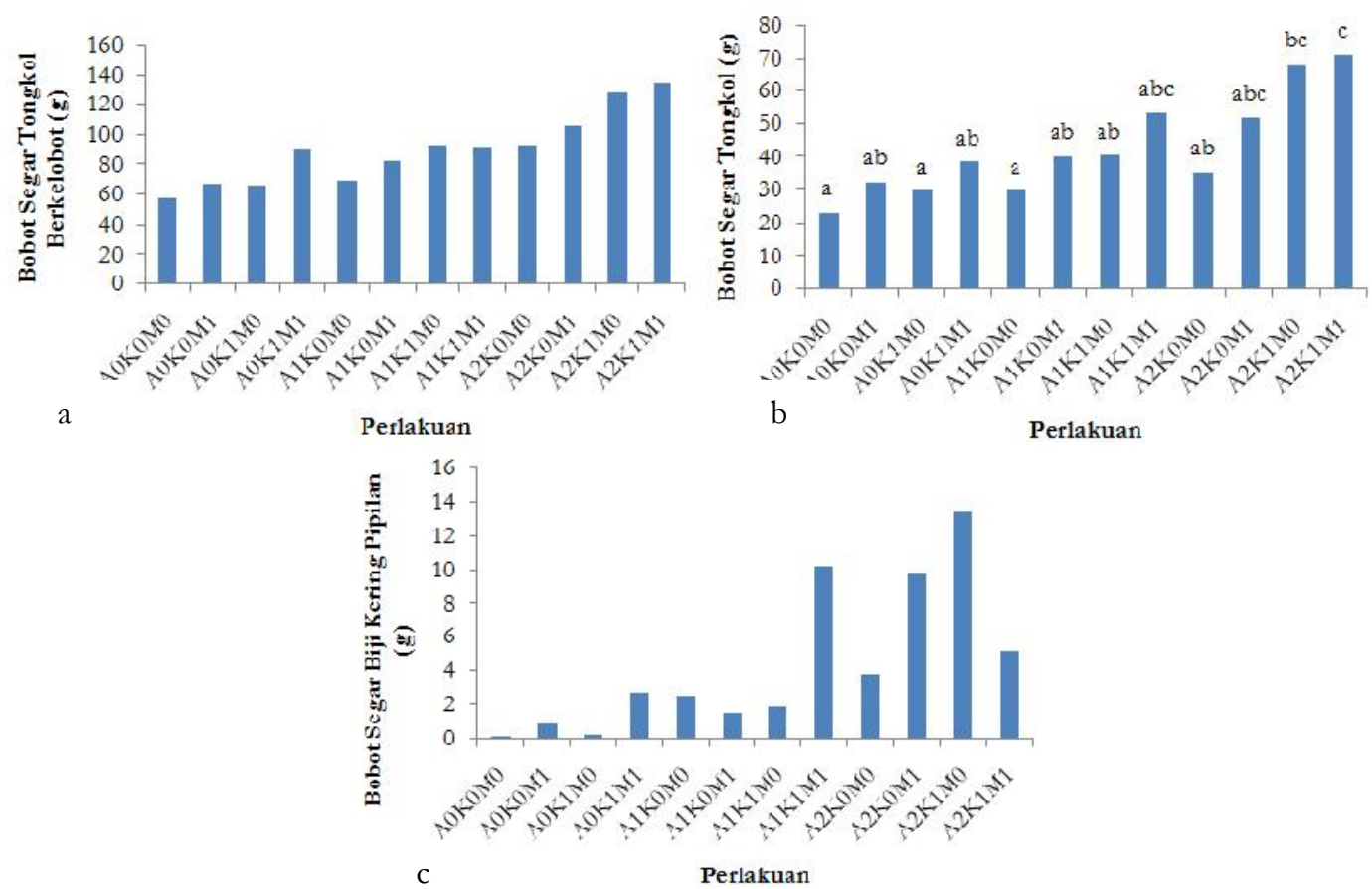

Gambar 5 (a). Rerata bobot segar tongkol berkelobot, (b). Rerata bobot segar tongkol, (c).Rerata bobot segar biji kering pipilan.

Keterangan: Kode perlakuan tertera pada Tabel 1, huruf yang sama diatas batang menunjukkan perlakuan tidak berbeda nyata pada uji lanjut Duncan 5\%.

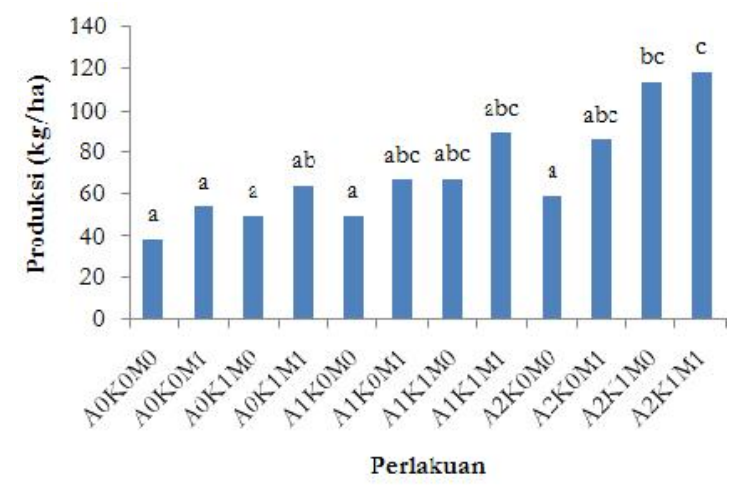

Gambar 6. Rerata produksi jagung.

Keterangan: huruf yang sama diatas batang menunjukkan perlakuan tidak berbeda nyata pada uji lanjut Duncan 5\%., Kode perlakuan tertera pada Tabel 1. 


\section{Jumlah spora}

Jumlah spora tertinggi terdapat pada perlakuan A2K1M1 yaitu sebesar 89 spora, sedangkan jumlah spora terendah terdapat pada perlakuan kontrol yaitu sebesar 60 spora (Gambar 7a). Kombinasi abu terbang batubara, kompos tandan kosong kelapa sawit dan mikoriza menunjukkan pengaruh yang sangat nyata. Peningkatan spora sejalan dengan rendahnya ketersediaan $\mathrm{P}$ dalam tanah karena tanaman cenderung memanfaatkan mikoriza dalam memperoleh unsur hara. Sesuai dengan Grant et al. (2005) yang menjelaskan bahwa ketersediaan $\mathrm{P}$ yang tinggi dalam tanah dapat menurunkan asosiasi mikoriza, sebaliknya jika ketersediaan $\mathrm{P}$ rendah maka akan meningkatkan terbentuknya mikoriza pada tanaman, karena pada tanah yang masam tanaman cenderung memanfaatkan mikoriza sebagai salah satu cara untuk memperoleh unsur hara dalam tanah. Noertjahyani (2011) juga menyatakan kandungan
$\mathrm{P}$ yang tinggi dan kandungan $\mathrm{C}$ lebih dari $2 \%$ akan menghambat pertumbuhan hifa propagaul, perkecambahan spora dan inisiasi kolonisasi akar.

\section{Persentase koloni akar}

Persentase koloni akar menunjukkan seberapa besar mikoriza menginfeksi akar. Persentase koloni akar yang tertinggi terdapat pada perlakuan A2K1M1 yaitu sebesar $73,33 \%$ dan terendah terdapat pada perlakuan kontrol yaitu sebesar 20\% (Gambar 7b). Pemberian abu terbang batubara, kompos tandan kosong kelapa sawit dan mikoriza berpengaruh sangat nyata terhadap persentase koloni akar. Koloni akar ditandai dengan adanya hifa dan misellium yang berwarna biru pada akar yang diamati.

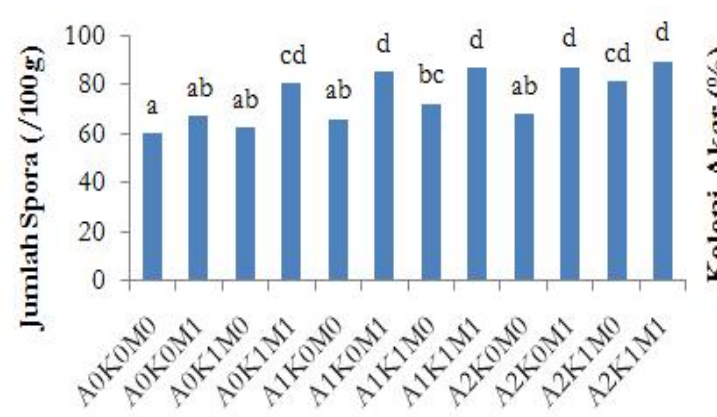

Perlakuan

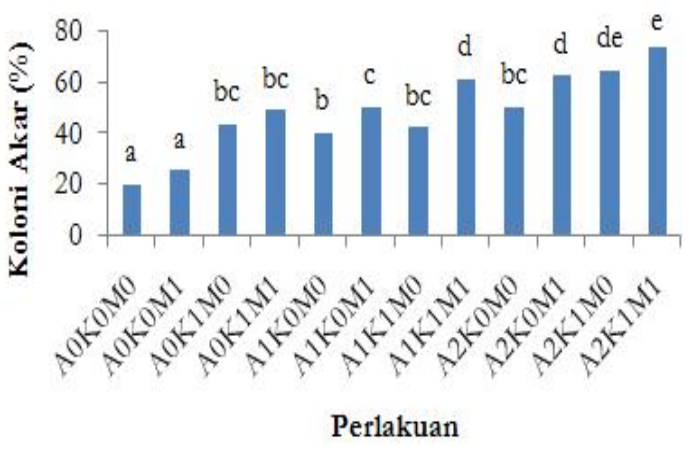

Perlakuan

Gambar 7 (a). Rerata jumlah spora, (b). Persentase koloni akar

Keterangan: huruf yang sama diatas batang menunjukkan perlakuan tidak berbeda nyata pada uji lanjut Duncan 5\%. Kode perlakuan tertera pada Tabel 1.

Meningkatnya koloni akar seiring dengan meningkatnya serapan P. Abu terbang batubara memiliki kandungan $\mathrm{P}$ sangat tinggi sehingga mampu diserap tanaman dengan bantuan mikoriza yang ditandai dengan adanya infeksi akar. Tingginya infeksi akar menunjukkan semakin aktif mikoriza memperluas daerah serapan dan menginfeksi akar. Sesuai dengan pendapat Musafa et al.. (2015) menyatakan bahwa semakin tinggi derajat infeksi mikoriza maka semakin aktif mikoriza tersebut memperluas daerah serapan akar terhadap air dan unsur hara serta menginfeksi akar.

\section{Kesimpulan}

Dibandingkan dengan kontrol, perlakuan 20 t ha $a^{-1}$ ATB +10 t ha $^{-1}$ KTKKS + 5 spora mikoriza per $\mathrm{kg}$ tanah merupakan perlakuan yang efektif dalam mempengaruhi pertumbuhan jagung. Perlakuan $20 \mathrm{t} \mathrm{ha}^{-1}$ ATB +10 t ha $^{-1}$ KTKKS + tanpa mikoriza menunjukkan P-tersedia yang paling tinggi, dikarenakan pada perlakuan dengan penambahan mikoriza, $\mathrm{P}$ yang tersedia langsung diserap sehingga nilai P-tersedia lebih kecil. Perlakuan $40 \mathrm{t} / \mathrm{ha}$ ATB $+10 \mathrm{t}$ 


\section{Jurnal Tanah dan Sumberdaya Lahan Vol 6 No 2 : 1261-1272, 2019 e-ISSN:2549-9793, doi: 10.21776/ub.jts1.2019.006.2.7}

$\mathrm{ha}^{-1}$ KTKKS +5 spora mikoriza per $\mathrm{kg}$ tanah merupakan perlakuan yang efektif dalam mempengaruhi serapan $\mathrm{P}$ yaitu sebesar $0,081 \mathrm{~g}$ $\operatorname{tanaman}^{-1}$ (mengalami peningkatan sebesar 5,04\%) dan produksi jagung yaitu sebesar $118,33 \mathrm{~kg} \mathrm{ha}^{-1}$ (mengalami peningkatan sebesar 2,09\%).

\section{Daftar Pustaka}

Akbar, B.R., Wardono Herry dan Susila M. Dyan. 2014. Pengaruh Variasi Jenis Air dan Temperatur Aktivasi dalam Campuran Fly Ash Bentuk Pelet terhadap Prestasi Mesin dan Emisi Gas Buang Sepeda Motor Bensin 4 Langkah. JURNAL FEMA, Vol. 2 No. 1.

Ekowati, Diah dan Mochamad Nasir. 2011. Pertumbuhan Tanaman Jagung (Zea mays L.) Varietas Bisi-2 pada Pasir Reject dan Pasir Asli di Pantai Trisik Kulonprogo (The Growth of Maize Crop (Zea mays L.) BISI-2 Variety on Rejected and non Rejected Sand at Pantai Trisik Kulon Progo. J. Manusia dan Lingkungan, Vol. 18, No.3 : 220 - 231.

Fahmissidqi, Dimas. 2016. Pengaruh Pemberian Berbagai Dosis Fungi Mikoriza Arbuskular terhadap Pertumbuhan Vegetatif Tanaman Kedelai (Glycine max L. Merr.). Jurnal Agroekotek 8 (1) : 47 - 55.

Fahrunsyah, Kusuma, Z., Prasetya, B. and Handayanto, E. 2018. Improvement of some chemical properties of an Ultisol of East Kalimantan through an application of combined coal fly ash and oil palm empty fruit bunch. Bioscience Research, 15(3), 1805-1814.

Grant Chyntia, Shabtai Bittman, Marcia Montreal, Christian Plenchette, and Christian Morel. 2005. Soil and Fertilizer Phosphorus: Effects on Plant P Supply and Mycorrhizal Development. Canadian Journal of Plant Science. Vol. 85 : 3-14.

Haryawan, Budi, Jurnawaty Sofjan dan Husna Yetti. 2015. Pemberian Kompos Tandan Kosong Kelapa Sawit dan Pupuk N, P dan K terhadap Pertumbuhan dan Produksi Tanaman Jagung Manis (Zea mays. L Var Saccarata Sturt). Jom Faperta Vol. 2 No. 2.

Hasanudin dan Bambang Gonggo M. 2004. Pemanfaatan Mikroibia Pelarut Fosfat dan Mikoriza untuk Perbaikan Fosfor Tersedia, Serapan Fosfor Tanah (Ultisol) dan Hasil Jagung (pada Ultisol). Jurnal Ilmu-Ilmu Pertanian Indonesia. Vol. 6 No. 1 : 8-13.

Herviyanti, Chici Anche, Gusnidar, dan Irwan Darfis. 2012. Perbaikan Sifat Kimia Oxisol dengan Pemberian Bahan Humat dan Pupuk P untuk Meningkatkan Serapan Hara dan Produksi Tanaman Jagung (Zea mays, L.). Jurnal Solum Vol. IX No. 2 : 51-60.

Made, Usman. 2010. Respons Berbagai Populasi Tanaman Jagung Manis (Zea mays saccharata Sturt.) terhadap Pemberian Pupuk Urea. J. Agroland 17 (2) : 138 - 143.

Musafa, M.K., Luqman Qurata Aini dan Budi Prasetya. 2015. Peran Mikoriza Arbuskula dan Bakteri Pseudomonas fluorescens dalam Meningkatkan Serapan P dan Pertumbuhan Tanaman Jagung pada Andisol. Jurnal Tanah dan Sumberdaya Lahan Vol. 2 No. 2: 191 197.

Nasution, R.M., Sabrina, T. dan Fauzi. 2014. Pemanfaatan jamur pelarut fosfat dan mikoriza untuk meningkatkan ketersediaan dan serapan $\mathrm{P}$ tanaman jagung pada tanah alkalin. Jurnal Online Agroekoteknologi, Vol. 2, No. 3: 1003 - 1010.

Noertjahyani. 2011. Respon Pertumbuhan Kolonisasi Mikoriza dan Hasil Tanaman Kedelai sebagai Akibat dari Takaran Kompos dan Mikoriza Arbuskula. Jurnal Ilmiah Pertanian Paspalum 10(1) : 46-70.

Prasetyo, B., H., dan Suriadikarta, D., A. 2006. Karakteristik, Potensi, dan Teknologi Pengelolaan Tanah Ultisol untuk Pengembangan Pertanian Lahan Kering di Indonesia. Jurnal Litbang Pertanian, 25 (2).

Rini, Hazli Nurdin, Hamzar Suyani, Teguh B. Prasetyo. 2009. Pemberian Fly Ash (Abu Sisa Boiler Pabrik Pulp) untuk Meningkatkan pH Tanah Gambut. J. Ris. Kim. Vol. 2 No. 2.

Same, Made. 2011. Serapan Phospat dan Pertumbuhan Bibit Kelapa Sawit pada Tanah Ultisol Akibat Cendawan Mikoriza Abuskula. Jurnal Penelitian Pertanian Terapan Vol. 11 (2): 69-76.

Simarmata, T. dan E. Herdiani. 2004. Efek Pemberian Inokulum CMA dan Pupuk Kandang terhadap $\mathrm{P}$ tersedia, retensi $\mathrm{P}$ dalam Tanah dan Hasil Tanaman Bawang Merah (Allium ascalonicum L.). hlm $14-20$ di dalam Prosiding : Pemanfaatan Cendawan Mikoriza untuk Meningkatkan Produksi Tanaman pada Lahan Marginal. Asosiasi Mikoriza Indonesia-Universitas Jambi.

Sinuraya, Mestika Amelia, Asil Barus dan Yaya Hasanah. 2015. Respons Pertumbuhan dan Produksi Kedelai (Glycine max (L.) Meriil) terhadap Konsentrasi dan Cara Pemberian Pupuk Organik Cair. Jurnal Agroekoteknologi. Vol.4. No.1.

Sipayung, Evan Sanjaya, Gantar Sitanggang dan M. M. B. Damanik. 2014. Perbaikan Sifat Fisik dan Kimia Tanah Ultisol Simalingkar B Kecamatan Pancur Batu dengan Pemberian Pupuk Organik Supernasa dan Rockphosphit serta Pengaruhnya terhadap Produksi Tanaman Jagung (Zea mays L.). 
Jurnal Tanah dan Sumberdaya Lahan Vol 6 No 2 : 1261-1272, 2019

e-ISSN:2549-9793, doi: 10.21776/ub.jts1.2019.006.2.7

Jurnal Online Agroekoteknologi. Vol. 2 No. 2 : 393 403.

Subandi, M., Hasani, S. dan Satriyawan, W. 2017. Efisiensi Pupuk Nitrogen Dan Fosfor Dengan Penambahan Pupuk Hayati Pada Tanaman Jagung (Zea mays L.) Varietas Pertiwi-3. Vol. 10 No. 1.

Suharno dan Retno Peni Sancayaningsih. 2013. Fungi Mikoriza Arbuskula: Potensi Teknologi Mikorizoremediasi Logam Berat dalam Rehabilitasi Lahan. Bioteknologi 10 (1): 37-48.
Syahputra, Ewin, Fauzi dan Razali. 2015. Karakteristik Sifat Kimia Sub Grup Tanah Ultisol di Beberapa Wilayah Sumatera Utara. Jurnal Agroekoteknologi. Vol. 4 No.1. 